\title{
A computer-based informal environmental management system for agriculture
}

\author{
K A Lewis \& K S Bardon
}

Department of Environmental Sciences,

University of Hertfordshire,

Hatfield,

Herts,

AL10 9AB, UK

Tel: 44 (0) 1707284582

Fax: 44 (0) 1707285258

Email: K.A.Lewis@herts.ac.uk 


\title{
A computer-based informal environmental management system for agriculture
}

\author{
K A Lewis \& K S Bardon \\ Department of Environmental Sciences, University of Hertfordshire, \\ Hatfield, Herts, AL10 9AB, UK
}

\begin{abstract}
This paper discusses a practical, computerised eco-management system for agriculture which has been developed at the University of Hertfordshire, UK for use by farmers and their advisers to encourage more sustainable practices. The research and software development has been funded by the UK's Ministry of Agriculture, Fisheries and Food and the Milk Development Council. The computerised system helps to measure environmental performance by evaluating an eco-rating that compares actual farm practices and site specific details with what is perceived to be the best practice for that site using an expert system together with scoring and ranking techniques. The eco-ratings system utilises a positive-negative scale to aid transparency and interpretation. In practical terms this means that undesirable and unsustainable activities will lead to negative eco-ratings. Activities which adhere to the principles of best practice and sustainable agriculture will lead to positive eco-ratings. The zero position may then be interpreted as representing an environmentally benign activity. In support of the assessment, the system incorporates modules to explore 'What-If' scenarios and a hypertext information system. This paper describes the approaches and methodologies used to develop the eco-ratings and outlines the software which utilises these indices within a comprehensive decision-support framework.
\end{abstract}

KEYWORDS: Environmental Impact by Agriculture; Decision Support System; Environmental Management; Sustainable Agriculture.

\section{SOFTWARE AVAILABILITY}

Name of software: EMA (Environmental Management for Agriculture)

Contact address: Kathy Lewis at the Department of Environmental Sciences

University of Hertfordshire

College Lane, Hatfield, Herts, AL10 9AB, UK

Telephone: $\quad 44(0) 1707284582$

Fax: $\quad 44$ (0) 1707285258

e-mail: $\quad$ K.A.Lewis@herts.ac.uk

Year first available: Spring 1998

Hardware required: IBM PC or compatible machine, 486 or better preferably a Pentium

Software required: WINDOWS operating system (version 3.1 or better including 95)

The programming language used is Visual Basic Professional Edition, however Professional FORTRAN and C have also been used for some of the mathematical computational routines. ACCESS has been used for the database management and Word 6 was used as the authoring tool for the hypertext information system.

\section{INTRODUCTION}

Following the end of World War II, there was an urgent need for European Agriculture to become more productive and so ensure that European food production became self-sufficient. This resulted in the establishment of the EC's Common Agricultural Policy (CAP) in 1962. Through a variety of financial and technological initiatives, high levels of productivity were actively encouraged. The policy was so successful that within twenty years food surpluses were extreme and severe environmental penalties were becoming apparent. Environmental concerns have grown considerably since that time and are currently focusing on the increasing and uncontrolled use of artificial inputs (e.g. chemical pesticides and inorganic fertilisers) and on the degradation and loss of rural areas. However, environmental impacts are not confined to these alone. Agricultural air emissions of ammonia, methane and nitrous oxide are contributing to poor air quality and global warming. According to the Council for Europe (1992) soil degradation due to erosion, loss of fertility and contamination is serious in parts of Europe. The UK's Ministry of Agriculture, Fisheries and Food have 
recently warned that climate change, extreme weather conditions and changes in land management practices could lead to greater soil erosion problems in the future (FW, 1997). Water pollution incidents arising from agricultural mis-management are widespread and accounted for $16 \%$ of category 1 (major) incidents in the UK in 1994 (EA, 1996). These, coupled with poor management of the natural resource bank and decreasing biodiversity provide compelling evidence that current agricultural practices are not sustainable (CPRE \& WWF, 1996).

Accepting the UNED (1994) roundtable's description of sustainable agriculture i.e. that it is a conceptual approach to better resource management and not a clearly defined end state, there are obviously a number of measures that any individual farmer can take to become more sustainable. These include, adopting a more discriminating use of inorganic fertilisers, using less chemical pesticides, considering the use of other methods of pest control such as the techniques promoted by Integrated Crop Management (e.g. LEAF, 1995), ensuring efficient use of natural resources and adopting conservation measures and sound management procedures for wildlife, habitats and landscape features.

The problems of how to achieve environmental protection while still ensuring a profitable business is a challenge to the farmer. The decision making process requires careful appreciation of all the risks and benefits. Environmental protection needs to be balanced against cost of implementation. The farmer needs to be able to assess his current situation and identify potential areas for change. Often expert help will be needed. However, there is no shortage of information and much practical guidance is available (e.g. MAFF \& HSC, 1990; MAFF, 1991,1992,1993; IOBC, 1993; FWAG, *). The type and severity of impact depend on site specific features including the activities that are carried out on the farm (crop production, crop protection, livestock management etc.) and local conditions such as the soil type, underlying geology, meteorological conditions and the absence or presence of sensitive environmental features such as water bodies or woodlands. The real problem facing farmers is how to use the available, but very general, information to develop a coherent action plan for their specific situation. The answers are rarely straightforward. Many factors are inter-related and often require value judgements.

There are many techniques for assessing environmental performance which could be applied to a farm. Formal environmental management systems such as ISO14001 (1996) and techniques such as Life Cycle Assessment (Anderson et al, 1994; Hemming, 1994; Lee et al, 1995) and Environmental Impact Assessment (Leopold et al, 1971; Munn, 1979; Hobbs, 1985) could all be applied to agricultural processes. However, within the UK, the agricultural industry appears disinterested in adopting them probably due to the relatively high manpower demands, their reliance on hard data and the farmers inability to see any short term market benefits from using them (Newbold et al, 1997).

The indicator principle has been used for decades to monitor trends and track improvement progress (Hunsaker \& Carpenter, 1990). Indicators and indices have a growing importance in environmental assessment, monitoring (OECD, 1991) and in sustainable development issues. Many different types of indicators are used in agriculture for environmental monitoring. These include familiar measures such as soil nutrient and organic matter levels, bio-indicators such as earthworm and other invertebrate counts, species counts for birds and mammals and those which are based upon biophysical analysis which can be used to assess the impact of land use such as the amount of evapotranspiration per unit of land area.

Indicators and indices can be used for a wide variety of purposes, such as to assess current conditions, predict trends, compare situations, to evaluate policy implementation and to monitor ecological degradation. However, neither indicators nor indices, including those developed for monitoring UK National Sustainabilty (DoE, 1996), are particularly useful to individual businesses for environmental assessment purposes in the short term. Despite their undeniable value, a single measurement can not be related directly to environmental performance. It is the information derived from time trends that provide this information. Consequently, short term benefits will not be obvious. There are several other problems associated with indices and indicators related to their usefulness to individual businesses. Quite complex indicators and indices are often necessary in order to cope with the variable space-time scales associated with agricultural processes. Many of the national indicators are not easily transferable to the local or regional scale due to the costs and resources required to collect the data such as those relating to climate change, ozone depletion or those based upon complex scientific measurements. Some indicators and indices may be influenced strongly by local factors but factors which are beyond the control of any individual business. For example those related to air quality in a heavy industrialised area or those based on a biological species count which could be affected by diseases or severe weather conditions. These external influences create problems when trying to evaluate the actual affect the environmental action plans of a single business (i.e. the farm). 
Various researchers, world-wide, are currently developing computer-based tools for assessing the environmental impact of agriculture. The farming community is not known, as yet, for its interest in computers. However their uptake of computer-based technology is growing and this is supported by the establishment of EUNITA (European Network for Information Technology in Agriculture). EUNITA's goal is to promote the use of information technology in agriculture. Other recent initiatives include the release of various Internet sites dedicated to agricultural businesses. These include, for example, the Rural Business Network (RBN, 1996), which is a subscription service providing information for agricultural, horticultural and land/property based businesses, and the on-line publication of several agricultural magazines and journals.

The vast majority of the research currently available is focused on the fate and transport of a pollutant in the environment and on one distinct impact such as nitrate leaching (e.g. Bradbury et al, 1993; Lord, 1992) or the transport of pesticides through the environment (e.g. Pinder et al, 1993; Reus \& Pak, 1993; Taylor, 1995; Van der Werf \& Zimmer, 1996). These individual solutions, while valuable, do not promote an integrated approach to impact minimisation, they do not help to identify the 'best practical environmental option' nor do they address the problems of environmental trade-offs. Although they allow scientists and policy makers to develop a detailed insight into environmental pathways and thus aid the development of novel environmental solutions, this type of information is not often helpful in identifying practical methods of tackling the problem at the source.

The University of Hertfordshire, in collaboration with two leading UK agricultural research establishments: ADAS and IACR-Rothamsted, have developed a practical, computer-based system, EMA, to support environmental management in agriculture and to encourage more sustainable practices. The system has been designed to be used by farmers and farm advisers. EMA acts as both a decision analysis and decision support system and helps to overcome many of the problems highlighted here. Principally, the software system is an exercise in technology transfer. It is broad-based addressing the farm as an entire process and attempts to bring together essential information required to minimise environmental impacts. Classical type simulation models often rely heavily on detailed input data. This data is often extremely difficult, time consuming and expensive to collect and, consequently, has a discouraging effect on potential users. EMA uses a simple but effective technique relying on input data and information readily available on the farm or that stored in the systems extensive databases.

\section{THE METHODOLOGY}

The main objective of the computer system is to allow measurement and monitoring of environmental performance. This is achieved by the derivation of activity-based eco-ratings. Actual farm practices, considering site specific details, are compared with what is perceived to be best practice for that site using an expert system approach together with scoring and ranking techniques.

The eco-ratings are concerned specifically with two main issues. Firstly, human actions, activities and processes which cause environmental impacts, particularly those which may have a marked effect when amassed on a global scale over time. Secondly, with the toxicological and physico-chemical properties of the pollutants, where appropriate, which affect the fate and transport of the pollutant in the environment and thus affect the potential for environmental change.

The majority of indicators and indices used in environmental assessment and monitoring have a purely positive value often ranging from zero to a large positive number or infinity. For example, Ott's (1978) water quality index or the concentration of a pollutant in the atmosphere. This can cause problems with interpretation and transparency of the index value. Usually, some comparison with historical data or with a defined scale is necessary to identify whether or not the data obtained represents good or bad news. Consequently, in the methodology described here a slightly different approach was adopted. Individual eco-ratings are determined for each activity (i.e. crop production, crop protection, habitat management etc.), each is then normalised to a common scale. In order to aid transparency and understanding, the eco-rating values may be either positive or negative. In practical terms, undesirable and unsustainable activities such as those leading to serious nitrate leaching, water pollution or habitat degradation will lead to negative eco-ratings. Activities which adhere to the principles of best practice and sustainable agriculture such as improving the quality of wildlife habitats or using integrated pest management (EIF, 1995) techniques would lead to positive eco-ratings. The zero point reflects a neutral or benign activity. 
The eco-rating scale has been set at \pm 100 . The most important aspect regarding the scale range is that it should allow easy visualisation and understanding of the eco-ratings and benchmarks. For example mentally visualising an eco-rating of +65 on a \pm 100 scale range is much simpler than trying to visualise +455 on a \pm 700 scale range.

For some activities the full positive-negative scale may not be utilised. There are two main reasons for this. Firstly, the activity may have no real environmental benefit but be necessary to protect financial investments. For example, the use of pesticides for arable crop protection. It may be argued that, in some circumstances, pesticides do have an environmentally beneficial role to play such as eliminating non-native, proliferous species which may be suffocating more desirable native species or for clearing rivers choking on excessive aquatic weeds. However, applications of pesticides on field crops are generally made to protect yields and quality. While this may be essential to ensure the short term business viability, the longer term sustainability issues also need to be seriously considered. Secondly, the activity may be an unavoidable consequence of the business but have no potential for environmental gain such as waste generation or the use of natural resources. In these cases the eco-ratings span the negative portion of the scale and best practice would lead to an ecorating close to zero.

Each activity is given the same default weighting. However, these default weights can be over-ridden by the system user to allow local objectives and issues to be given greater significance or a different priority.

Farm activities, such as those shown in Figure 1, can be roughly divided into two types. Firstly, those which are associated with the entire farm such as habitat conservation; energy and water efficiency; storage, handling and waste management of organic and inorganic fertilisers; pesticide storage, waste management, etc.. These activities rely heavily on visual and qualitative information rather than data. For example, when and how hedgerows are trimmed, whether or not farm buildings are insulated or whether or not the pesticide store has a non-permeable base, running water and a lockable door (Lewis et al, 1997). The second type refers to those activities which, in whole or in part, are applicable to specific fields and not necessarily the whole farm. For example the application of fertilisers or pesticides (Lewis et al, 1997b) to a specific crop.

If quantitative data for individual fields are available then the fate and transport of pollutants can be more readily tracked and a more detailed analysis of environmental performance can be carried out. Depending upon the activity type, different approaches were taken to develop the eco-ratings.

\subsection{Visual and Qualitative Data}

The development of the eco-ratings which rely on visual or qualitative data involved a number of steps. Firstly, the individual tasks which contribute to the completion of the activity were identified. An example is shown in Table 1 which shows some of the tasks associated with crop protection.

Completion of each task involves a number of separate steps and associated with each step are a variety of options which may be used to complete that step. These were also identified. For example associated with task 6c (i.e. waste management procedures for, say, empty pesticide containers) the individual steps may include rinsing it, piercing or crushing and then actual disposal. For each step the farmer has a number of options available. These will range from the environmentally acceptable options to the unacceptable and extreme options. For example, options for disposal may include burying, burning, sending to landfill or incineration via a licensed waste operator and the indiscriminate and illegal dumping of wastes (i.e. fly tipping). Each possible option is assigned a score $\left(\mathrm{S}_{\mathrm{o}}\right)$ depending on how it compares with best practice. This score assigning process in itself can be highly subjective and controversial particularly as it is difficult to implicitly define "good" and "bad" in complex systems such as agriculture. Scores have been assigned by consensus among the researchers involved in the project. In future versions of the software, a more disciplined approach involving a broader panel of expertise is planned using a technique such as Delphi (Gupta \& Clarke, 1996; Murry \& Hammons, 1995). Scores are summed across steps to derive a total $\left(S_{n}\right)$ for the task $(n)$, weighted $\left(w_{n}\right)$ depending on the relative significance of that task to the activity overall and summed to derive the eco-rating for that activity $\left(E_{a}\right)$. Weighting factors associated with individual tasks all initially have an equal default value. These can be altered by the system user to reflect local priorities if required. The scoring of an activity can be described by equations (1) and (2):

$$
\mathrm{S}_{\mathrm{n}}=\sum \mathrm{S}_{\mathrm{o}}^{\mathrm{o}=\text { no. steps }}
$$




$$
0=1
$$

and

$$
\mathrm{E}_{\mathrm{a}}=\sum_{\mathrm{n}=1}^{\mathrm{n}=\text { no. tasks }} \mathrm{W}_{\mathrm{n}} \mathrm{S}_{\mathrm{n}}
$$

Consider the task of 'hedge management' associated with the activity 'Habitat Conservation'. Retention and management of hedgerows on the farm is one of the most important aspects of farmland conservation but one that is often neglected. The eco-rating system includes an assessment of the quality of unlaid hedgerows by scoring length, average height, and width, the percentage gap, percentage composition of native and non-native species, when and by how much hedges are trimmed and the number of standard trees present. The function used to assess length, deriving a score $\left(\mathrm{H}_{\mathrm{R}}\right)$ is given in equation (3). $\mathrm{L}_{\mathrm{p}}$ is the length of hedgerow planted in the last year and $L_{R}$ is the length removed. $L$ is the length at the start of the year.

$$
\mathrm{H}_{\mathrm{R}}=\operatorname{Int}\left(\left(\mathrm{L}_{\mathrm{p}}-\mathrm{L}_{\mathrm{R}}\right) / \mathrm{L}\right) \times 9
$$

If all hedges are removed in the assessment year a score of -9 is awarded. The maximum score is limited to +9 given when the length of hedgerow is increased by $100 \%$ or more.

In a situation where $180 \mathrm{~m}$ of hedgerow were planted and $65 \mathrm{~m}$ were removed and at the start of the year there was a total length of $500 \mathrm{~m}, \mathrm{H}_{\mathrm{R}}$ would have a value of 2 . For unlaid hedges, the baseline rating $\left(\mathrm{H}_{\mathrm{R}}\right)$ is enhanced depending upon the shape and quality of the hedge. The scores assigned for hedge height range from 0 for hedges less than 1 metre high to +3 for hedges of 4 metres or more. For hedge width scores range from 0 for widths less than 1 metre to +3 for those of 3 metres or more wide.

\subsection{Quantitative Data}

Where adequate and reliable data are likely to be available a different approach for the eco-rating development was taken. The main areas where these data are most likely to be available is regarding field applications of fertilisers, lime and pesticides. In these cases the site specific factors which influence the occurrence and severity of the impact were identified, as were the toxicological and physico-chemical properties of the pollutants which affect their fate and transport in the environment.

For fertiliser applications the main environmental risk is concerned with nitrate leaching and the contamination of drinking water supplies. Many parameters effect the amount of nitrate lost. However, the principal factor is the amount of nitrate available in the soil for leaching. This is determined by several factors including the amount of nitrate applied as fertiliser and the application timing. Quantitative recommendations for the amounts and application timings are available to farmers in varying formats, one of the most commonly used in the UK is that produced by the UK's Ministry of Agriculture, Fisheries and Food (MAFF, 1994). These recommendations are based upon soil type, existing soil nutrient levels and the crop grown. Within the software a simple relative error calculation based upon the differential between actual application rates $\left(\mathrm{F}_{\mathrm{A}}\right)$ the recommended rates $\left(\mathrm{F}_{\mathrm{R}}\right)$ provides the baseline eco-rating $\left(\mathrm{F}_{\mathrm{F}}\right)$. This baseline factor is then enhanced by scores associated with other factors $(f(\mathrm{~A}))$ such as application timing, rainfall levels and soil type to establish a measure of the environmental impact and more specifically nitrate leaching. This is shown in equation (4) where $\beta$ ia a scaling factors and $\eta$ is the field size in hectares.

$$
\mathrm{F}_{\mathrm{F}}=\operatorname{INT}\left(\eta\left(\beta\left(\mathrm{F}_{\mathrm{R}}-\mathrm{F}_{\mathrm{A}}\right) / \mathrm{F}_{\mathrm{R}}\right)+f(\mathrm{~A})\right)
$$

A worked example is given below. For the purpose of simplification and to aid the example's clarity it has been assumed that:

- fertiliser application timing matched that recommended;

- the levels of other soil nutrients have been maintained but no special attention was given to minimising the risk of losing phosphate;

- the risk of nitrate leaching is not enhanced as rainfall is below average and the excess of nitrogen applied is not greater than $40 \mathrm{~kg} / \mathrm{ha}$ as this is generally considered serious; 
- best practice and regulatory compliance has been carried out with respect to the site specific details. Consequently, the last part of the function i.e. $f(\mathrm{~A})$ has been given a value of 0 out of \pm 10 .

Consider a single field, 10 hectares in size having a sandy soil, a soil nitrogen supply of $100 \mathrm{~kg} / \mathrm{ha}$ ( $\mathrm{N}$ index $=$ 0 ). Winter Oilseed Rape was grown, $\mathrm{N}$ fertiliser was applied in the spring at a rate of $180 \mathrm{~kg} / \mathrm{ha}$. Rainfall was slightly below average at around $700 \mathrm{~mm}$ per year. The MAFF (1994) recommendations give a rate of 160 $\mathrm{kg} / \mathrm{ha}$. $\beta$ is currently set at 10 .

Therefore:

$$
\begin{aligned}
& F_{F}=10(10(160-180) / 160)+0 \\
& F_{F}=-12.5 \text { on a scale range of } \pm 110 \\
& F_{F}=-11 \text { on a normalised scale range of } \pm 100
\end{aligned}
$$

In this manner negative scores are awarded where $\mathrm{N}$ has been applied in excess of the recommendations. If less nitrogen is applied then the score will be positive reflecting the low risk of nitrate leaching but the ultimate score will depend on sub-rules determining the level of risk associated with falling soil fertility.

For pesticide applications (Lewis et al, 1997b,c) the baseline eco-rating is derived from the hazard warning labels associated with the product. All pesticides in the UK carry mandatory label precautions relating to how and where that product can be used. These labels are assigned by MAFF's Pesticide Safety Directive and are based upon detailed and comprehensive data provided by the manufacturer for the purpose of licensing under the 1985 Food and Environmental Protection Act. If the pesticide is used in accordance with these precautions the environmental risk is minimised. There are around 90 different label precautions which can be numbered, categorised by target, scored and so ranked according to the severity of the risk. This is summarised in Table 2 .

The appropriate scores for each assigned label precaution are summed to derive the baseline eco-rating associated with the product $\left(\mathrm{LR}_{\mathrm{p}}\right)$. However, some label precautions are disregarded depending upon site specific factors. For example those associated with surface water are not considered if the site has no surface water or those associated with bees may be disregarded according to the application season and the absence or presence of flowering plants.

The baseline eco-rating is then enhanced by considering parameters which influence the fate and transport of the pesticides in the environment such as solubility $\left(\mathrm{S}_{\mathrm{sol}}\right)$, vapour pressure $\left(\mathrm{S}_{\mathrm{vp}}\right)$, soil half-life $\left(\mathrm{S}_{\mathrm{T} 0.5}\right)$, the octanol-water partition coefficient $\mathrm{K}_{\mathrm{ow}}$ as a measure of bioaccumulation and the organic-carbon partition coefficient $\mathrm{K}_{\mathrm{oc}}$ used within the GUS equation (Gustafson, 1989) to reflect soil mobility and the risk of leaching $\left(\mathrm{S}_{\mathrm{GUS}}\right)$. For each parameter five risk bands were assigned to overcome the problem of values varying with environmental conditions such as temperature, pressure and soil type. For each of the parameters a score was assigned according to the appropriate risk band. These were then summed for each active ingredient $\left(E_{j}\right)$. These values are then weighted by the proportion of active ingredient in the product $\left(\mathrm{Q}_{\mathrm{j}}\right)$ and summed to give a product value. The process can be described by the following equations where $\alpha$ is a scaling factor:

$$
\mathrm{LR}_{\mathrm{p}}=\sum \text { label precaution scores associated with product } \mathrm{P}
$$

and

and

$$
\mathrm{E}_{\mathrm{j}}=\mathrm{S}_{\mathrm{sol}}+\mathrm{S}_{\mathrm{vp}}+\mathrm{S}_{\mathrm{T} 0.5}+\mathrm{S}_{\mathrm{Kow}}+\mathrm{S}_{\mathrm{GUS}}
$$

$$
\mathrm{S}_{\mathrm{p}}=\operatorname{INT}\left(\left(\mathrm{LR}_{\mathrm{p}}\right)+\alpha \sum_{\mathrm{j}=1}^{\mathrm{j}=\text { no. a.i's in product }}\left(\mathrm{E}_{\mathrm{j}} \cdot \mathrm{Q}_{\mathrm{j}}\right)\right)^{\mathrm{IN}}
$$

Further enhancements to the eco-rating are then made by comparing actions with best practice and considering the level regulatory compliance. For example, has the number of permitted applications been exceeded? Was the dosage less than the maximum permitted? Was a particular insecticide repeatedly applied and so, possibly, encourage resistance? Was the harvest interval complied with?

In the development of an index for a single but complex process such as 'farm management' there is often lengthy discussion regarding whether or not sub-indices (e.g. those derived for individual activities) should be summed to produce a single score for the whole process (e.g. the farm). Many researchers argue both for and against aggregation (e.g. Thompson, 1990; Alberti \& Parker, 1991; Midmore \& Langstaff, 1995). In this 
system the decision was made to avoid summing across activities mainly because aggregation has a tendency to conceal important information and much can be gained if eco-ratings are presented individually. Within the EMA system the individual normalised eco-ratings are displayed together on a single screen, as shown in Figure 2, in order to allow simple comparison and identify areas where improvements are necessary, allowing easy prioritisation.

Development of an emissions inventory is a useful part of many techniques and methodologies used in determining environmental impact including Life Cycle Assessment and as part of the review procedures essential to the implementation of an environmental management system. An inventory is a detailed list of all emissions from a process into the environment (air, water and land). EMA estimates such an inventory for the farm under evaluation. This has been achieved using a variety of techniques including emission factors and heuristics. For example within the energy assessment module for each unit measure of fuel used (e.g. electricity, natural gas, LPG, coal etc.) air emissions are calculated using emission factors for carbon dioxide, carbon monoxide, sulphur dioxide, oxides of nitrogen and methane. Within the field by field fertiliser assessment modules releases of ammonia and nitrous oxide are estimated using emission factors. Nitrate leaching from both fertiliser applications and livestock grazing are determined using simple heuristical models. With respect to the emissions calculated absolute precision has not been given a high priority. The main aim was to provide 'ball park' estimates to boost awareness and understanding of emissions and to place emphasis on ensuring that:

- the scale of release is correct. For example, is the annual loss in the order of $10 \mathrm{~kg} / \mathrm{ha}, 100 \mathrm{~kg} / \mathrm{ha}$ or 1000 $\mathrm{kg} / \mathrm{ha}$. Whether the actual value is $10 \mathrm{~kg} / \mathrm{ha}$ or $15 \mathrm{~kg} / \mathrm{ha}$ is less of an issue in this type of application, and further levels of accuracy become meaningless particularly to farmers who have no control over external contributing factors such as rainfall and soil type and who may not be familiar with what constitutes a high or low level of nitrate loss under any particular set of circumstances.

- trends in losses properly reflect changes in practices. For example, nitrate leaching tends to be higher on some crops (e.g. irrigated vegetables) than on others (e.g. cereals). If the crop grown changes losses shown by the emissions inventory must reflect this;

- when ever possible environmental emissions, particularly with respect to nitrates and pesticides are related back to financial losses or gains and so to profitability.

As an example consider the lose of ammonia from fertiliser applications to land. This is estimated to be around $32 \mathrm{kt} \mathrm{NH}-\mathrm{N}$ per year, equivalent to $16 \%$ of the annual UK total loss. There are two main types of $\mathrm{N}$ fertiliser (i) urea which has an emission rate of $10.4 \%$ of the total $\mathrm{N}$ applied and (ii) other fertilisers including ammonium nitrate which have an emission rate of $0.8 \%$. Therefore in a field of 10 ha in size where fertiliser is broadcast at a rate of $200 \mathrm{~kg} / \mathrm{ha} \mathrm{N}$ as urea, an estimated 208 $\mathrm{kg}$ of $\mathrm{NH}_{3}-\mathrm{N}$ would be lost from that field. However, if ammonium nitrate was used instead losses would be around $16 \mathrm{~kg}$ of $\mathrm{NH}_{3}-\mathrm{N}$.

\section{THE SOFTWARE}

The software has a single main operational mode in conjunction with two support modes as shown in Figure 3. The main mode is concerned with Performance Assessment. This determines the eco-ratings which describe environmental performance across all farm activities.

The first support mode, known as the Technical System, incorporates a collection of models, expert systems, databases and other utility modules to allow the user to examine 'What-If' scenarios to identify site specific solutions to environmental problems and so improve future eco-ratings. This mode helps the user identify solutions to problems identified in the Performance Assessment mode. For example, if the risk of soil erosion is highlighted as a problem then this mode can be used to identify appropriate abatement and control techniques. This part of the system includes:

- a module to identify the crops N, P and K requirements and the ideal application timing. This is based on the fertiliser recommendations published by the UK's Ministry of Agriculture, Fisheries and Food (MAFF, 1994). The user enters soil type, soil nutrient levels and the crop to be grown and the software returns information on the quantities of $\mathrm{N}, \mathrm{P}$ and $\mathrm{K}$ required together with advice on timings and any special requirements the crop might have with respect to trace elements, etc.. This module utilises a database containing crop nutrient information; 
- guidance on the main risks associated with different pesticides. The user specifies the crop and the pest and the system provides a list of approved pesticides. As different pesticides are selected from the list provided with the mouse, a visual icon display, based on the MAFF label precautions and other data, is shown. For example a fish icon is displayed where a certain pesticide presents a significant risk to aquatic species and/or a bee icon if there is a risk to honey bees. Other icons are used to communicate risks to animals, birds, groundwater and to show if the pesticide is a registered poison under the UK's Poisons Act 1972, Poisons List Order 1982 or the Poisons Rules 1982. This approach allows the user to easily identify an appropriate pesticide which presents the least risk to the specific site;

- a risk assessment approach is used to identify the site risk of soil loss due to wind and rain erosion;

- a waste management adviser provides information on a wide range of wastes generated on a farm including animal wastes, crop wastes, chemical wastes, packaging, oils, contaminated soils, discarded machinery etc. and provides guidance for minimisation, recycling, re-use and approved disposal methods.

The second support mode is a hypertext Advisory System containing:

- a legislation and regulation database for the UK and EU. Records are indexed by topic, date, regulation type, keyword and source;

- the main UK Codes of Good Practice. Most of those included have been produced by or on behalf of the UK government and other respected sources;

- a science library giving basic information on the interactions of agriculture and the environment;

- guidance on environmental management and auditing including ISO14000 series and the EU's EMAS;

- a contacts database, full index and glossary of terms.

Information is context-sensitively mapped and can be called from any where within EMA via a function key or command button. Significant use has been made of presenting information in a simple and user-friendly manner including bullet points, graphical displays and diagrams.

\subsection{Using EMA}

The first step in using EMA is to input the site specific data. This is achieved via the 'Farm Profile' screens (see Figure 4). This data includes information on:

- geographic location of the farm by UK postcode;

- local meteorological conditions (e.g. rainfall, prevailing wind direction, average temperatures);

- farm activities (e.g. arable/field crops, livestock husbandry, horticultural activities, etc.)

- any sensitive environmental features (e.g. surface water, principal aquifers, woodlands, boreholes);

- any special environmental designations (e.g. SSSI, ESA, NVZ);

- field by field details of soil type, soil nutrient assay data for nitrate, phosphate and potash,

organic matter levels, crops grown, $\mathrm{pH}$, grazing data, etc.

Although it is expected that the farmer or system user will have this type of data available, databases containing typical or average data are accessible if required. These include a soil database containing spatial information on soil types and associated features such as the location and types of aquifers, risk of nitrate leaching and soil erosion. A climate database stores spatial data on average rainfall, temperature and prevailing wind directions. For ease of use data is referenced in both databases by postcode. Although the data resolution is somewhat crude at a $10 \times 10 \mathrm{~km}$ grid square scale, the information is invaluable for educational/training purposes and as back-up when farm data is absent.

The amount of information which needs to be handled by EMA can become very large, especially as the farm being assessed may have many fields and each field may have different conditions and have multiple fertiliser and pesticide applications each season. Consequently, data input has been streamlined using checklists and spreadsheets. Data is elicited from the user in the simplest form possible. Often where actual numerical data is unlikely to be available, qualitative data are entered and this is translated into the required format by the software. Table 3 shows an example of how visual wind data is translated into a numerical format i.e. as speed in $\mathrm{km} / \mathrm{h}$ (adapted from MAFF \& HSC, 1990).

The software uses the farm profile information to select the appropriate expert system type rules which need to be applied. For example, if the farm is arable only, the rules relating to livestock management are not required. At a more detailed level crop nutrient recommendations vary with crop, soil type and nutrient levels already in the soil. Consequently, specific rules need to be applied to specific sites. Rules are incorporated into the software at the point of deriving the eco-ratings. Activity specific rules are stored in subroutines in the form of 'IF-THEN-ELSE' structures to identify the correct scores. For example : 


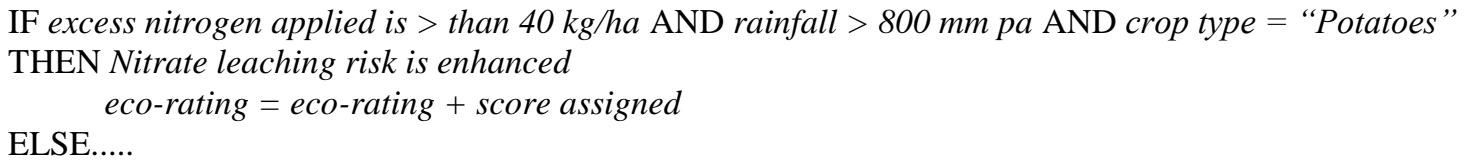

The second phase of using EMA concerns evaluating performance using the activity audits. For each activity, the user is required to enter specific information on how tasks are normally carried out. For example when ditches are dredged and what proportion are cleared each year. Once input data have been supplied, eco-ratings are calculated and also assigned one of five performance descriptors (i.e. good, above acceptable, acceptable, below acceptable and poor). Data can also be displayed graphically. Accompanying each assessment is a report and recommendations plus an estimate of the emissions resulting from the activity. Data for each activity can be stored in data files which can be recalled and edited as required in future performance assessments. The full process for using EMA is shown in Figure 5.

As each activity audit is completed, the eco-rating and the performance descriptor information is transferred to a farm performance screen where information for all activities can be compared (see Figure 2). The emissions data is collated and complied into a farms emissions inventory.

The computer system has been designed as an integrated package providing across the board support to farmers. One of the problems of this type of software is that it will require frequent updating. Consequently, the system has been designed on a modular basis whereby smaller pieces of software are plugged into and called from a central framework. This provides many advantages. It allows simple updating, upgrading and modification of the software. It also allows separate modules to be disengaged from the main system and used independently. Some parts of the system such as the Advisory mode and the individual modules within the Technical mode have a potentially wider audience than the Environmental Assessment mode which is directed solely towards farm businesses.

\section{EVALUATION}

Complete validation of any computer model or other advisory software system is impossible. Validation is normally intended to increase confidence in a technique with respect to its ability to successfully carry out a task. If it succeeds then its credibility increases. Validating a tool such as EMA is quite problematic in a real case-study situation. The eco-ratings derived are highly site-specific, depending upon site conditions and actual farming practices. Unlike simulation models expert systems can not, so easily, be tested against facts. Experts do not always agree. The best that can normally be done is to check that the conclusions and recommendations of the system broadly agree with the majority of expert thinking.

Validation and piloting of EMA is still being carried out. This process includes evaluation of the science by experts, peers and co-workers, demonstrations and presentations to the farming industry, hands-on workshop sessions for farmers, one-to-one sessions with individual farmers and analysis of case-study results (Lewis $e t$ $a l, 1997 \mathrm{c})$. Part of this process is being undertaken with a major UK food retailer where the system is installed on the computers of technical staff for evaluation and is being piloted independently with their growers. Feed back from these processes is used to modify and refine the software.

\section{CASE STUDY}

The following case study demonstrates the environmental performance eco-rating system with farm pesticide data.

The pesticide eco-ratings use only the negative portion of the eco-rating scale ( 0 to - 100$)$. Generally an ecorating numerically less than -40 can be associated with good practice. Higher values, those closer to zero, can be linked with those pesticides which are less environmentally toxic, while those closer to -40 will be relatively more toxic. Eco-ratings in the range of -40 to -70 may not necessarily represent unapproved applications but may indicate that an alternative chemical or an adjustment in practices may be environmentally beneficial. Eco-ratings below -70 usually mean very poor practices, undesirable operations or unapproved applications.

The farm in question is situated in the south east of England and occupies a total cropping area of around 800 hectares. It focuses on producing arable crops principally winter wheat (45\%), sugar beet (18\%) and potatoes $(8 \%)$. On one particular field cropping sugar beet part of the crop protection programme included the 
applications described in Table 4a. The individual eco-ratings and the field value for this programme is shown in Table $4 \mathrm{~b}$.

The eco-rating of -100 derived for the first application implies very poor practice. This value has been awarded as the product (fenpropidin+propiconazole) does not have approval under the UK's Control of Pesticide Regulations, 1986 (COPR) for sugar beet applications. Only approval for use as a fungicide on barley and winter wheat has been given for this product. Another problem identified is that the application was made in warm, sunny weather in a force 1 wind speed. The MAFF/HSC (1990) Code of Practice states that '...where there is little or no wind - force 1 or 0 - air movement tends to be unpredictable, particularly on warm days..... turbulent air movement may carry fine spray and vapour long distances...' consequently a risk of drift was identified and the performance rating was penalised although, in this case not significantly as no surface water is within $10 \mathrm{~m}$ of the feild boundary. These points coupled with the relatively toxic nature of the product reflected in the relatively large list of label warnings, has generated the minimum performance rating.

No problems were identified with applications 2,7 or 8 . All values lie above the -40 nominal boundary and all were approved applications under COPR. Although cypermethrin has an extensive label precaution list, best practice and a low application rate has generated a low eco-rating.

The slight difference between the eco-ratings determined for applications of ethofumesate+phenmedipham (3 \& 6) is due to several issues including the calmer winds in the latter application. The MAFF/HSC (1990) code warns against spraying herbicides in a force 3 and any pesticide in a force 4 or stronger and so the eco-ratings have been penalised in both cases. Although the applications are approved under COPR the two applications of the same herbicide in quite close succession reflect little concern for the risk of weed resistance developing and so the eco-ratings have been further reduced. The application rates are also relatively high compared with other applications. Under best practice conditions and an application rate of around $1 \mathrm{l} / \mathrm{ha}$ the eco-rating would be around -30 .

With respect to the eco-ratings derived for the three applications of metamitron $(4,5 \& 7)$. Two main issues were identified by the system. Firstly, the wind conditions under which spraying took place, particularly in the first tow applications, were again not best practice. Secondly, multiple applications of the same pesticide over a relatively short period of around 6 weeks raises concerns regarding weed resistance developing. Evidence (Heap, 1996) suggests that the development of weed resistance to certain herbicides is encouraged with continuous and frequent applications of the same pesticide or pesticide group because the population of resistant individuals increases as non-resistant individuals are killed. Future generations of the weeds are then much more likely to be resistant to that particular pesticide. Consequently, the eco-ratings have been penalised to reflect this.

Under best practice and an application rate of 1 1/ha an eco-rating of around -30 would have been awarded. At first glance it would appear from the number of label precautions that this value should be lower when compared with ethofumesate+phenmedipham. However, it should be noted that the eco-rating is comprised of two parts: (i) the label precautions and (ii) the physico-chemical properties of the individual active ingredients. In the case of ethofumesate+phenmedipham the bulk of the eco-rating comes from the label precautions. With respect to metamitron the bulk of the value comes from its physico-chemical parameters and the relatively large quantity of active ingredient in the formulation $(70 \% \mathrm{w} / \mathrm{w})$.

\section{DISCUSSION AND CONCLUSION}

An important requirement of any qualitative environmental evaluation system is a mechanism to enable all the different activities to be combined in a rational, reproducible and acceptable manner. One commonly used approach and that used by EMA, is simple scoring and ranking techniques where each activity, impact or indicator is assigned a numerical score based upon its magnitude or significance, with the total score representing the total impact. Examples of this are frequently cited in environmental impact assessments, for example Solomon et al (1977), and tend to be criticised for being simplistic in approach. However, this method does offer a good starting point and in many cases the only practical means where the underlying complexities are not fully understood. Another advantage of this approach is that it tends to be less demanding with respect to input data and so is well suited to the described application.

EMA acts as an environmental management system having similar objectives to formal systems such as EMAS or ISO14001 in as much as it aims to encourage continuous improvements in environmental performance and 
seeks to identify and control significant impacts. The computer system encourages environmentally sound decision making, helps ensure regulatory compliance, helps identify significant impacts and allows monitoring of progress. More specifically the system is:

- generic in the context of agriculture;

- proactive based upon the principles of anticipation and prevention;

- systematic based upon detailed documented procedures;

- provides instant access to a wealth of appropriate and context-sensitively mapped information.

The development of such a software package brings together all relevant information required for the user (i.e. the farmer or farm adviser) to ensure that farming practices are in line with our current understanding of best practice and where deficiencies are identified, cost effective and practical site-specific solutions can be suggested which suit the user. The major drawback of this system is that it requires frequent updating. Obviously, data such as that within the pesticides database will change frequently as new pesticides are registered and marketed and as others have their licences revoked. Legislation and regulation changes regularly, the MAFF codes of good practice are currently under review and science and technology will evolve. Consequently, current understanding of what is perceived to be best environmental practice will undoubtedly change - "a once and for all" definition is highly unlikely. The modular format and the gathering of activity-based rules into specific subroutines should allow these modifications to be made with little difficulty.

\section{ACKNOWLEDGEMENTS}

The authors gratefully acknowledge funding for this research project from the Ministry of Agriculture, Fisheries and Food and from the Milk Development Council. This paper expresses the views of the authors and not necessarily those of the sponsors.

\section{REFERENCES}

- Alberti, M. \& Parker, J.D. (1991) Indices of Environmental Quality: The Search for Credible Measures. Environmental Impact Assessment Review 11, 95-101

- Anderson, K., Ohlsson, T. \& Olsson, P. (1994) Life-Cycle Assessment (LCA) of Food Products and Production Systems. Trends in Food Science and Technology 5, 5, 134-138

- BCPC - Britich Crop Protection Council (1997) The UK Pesticide Guide 1997

- Bradbury, N.J., Whitmore, A.P., Hart, P.B.S. \& Jenkinson, D.S. (1993) Modelling the fate of nitrogen in crop and soil in the years following application of ${ }^{15} \mathrm{~N}$-labelled fertiliser to winter wheat. Journal of Agricultural Science Cambridge, 121, 363-379

- Council for Europe (1992) Recommendations number R(92) 8 on Soil Protection.

- CPRE \& WWF - Council for the Protection of Rural England \& World Wide Fund for Nature (1996) Growing Greener: Sustainable Agriculture in the UK.

- DoE - Department of the Environment (1996) Indicators of Sustainable Development for United Kingdom. London, HMSO

- EA - Environment Agency (1996) The Environment of England and Wales - A Snapshot

- EIF - European Initiative for Integrated Farming. (1996) Integrated Crop Management - The New Direction for European Agriculture.

- FW (1997) Farmers Weekly, Nov 14 - Nov 20. p17

- FWAG (Undated) Farming and Field Margins Information leaflet.

- Gupta, U.G. \& Clarke, R.E. (1996) Theory and Applications of the Delphi Technique: A Bibliography, 1975 to 1994. Technological Forecasting and Social Change 53, 185-211

- Gustafson, D.I. (1989) Groundwater Ubiquity Score: A Simple Method for Assessing Pesticide Leachability Environmental Toxicology and Chemistry, 8, pp339-357

- Heap, I.M. (1996) International Survey of Herbicide-Resistant Weeds. Annual Report

- Hemming, C. (1994) The Benefits of Life-Cycle Assessment in Practice. IBC Technical Services Ltd Conference London.

- Hobbs, B.F. (1985) Choosing How To Chose: Comparing Amalgamation Methods for Environmental Impact Assessment. Environmental Impact Assessment Review 5, 301-319 
- Hunsaker, C.T. \& Carpeter, D.E. (1990) Environmental Monitoring and Assessment. Programme Ecological indicators. Environmental Protection Agency 600/3-90-060

- IOBC (1993) International Organisation for Biological and Integrated Control of Noxious Animals and Plants. Commission "IP-Guidelines" Integrated Production: Principles and Technical Guidelines. Bulletin OILB 16(1)

- ISO 14001 (1996) International Organisation for Standardisation. Environmental Management Systems. Specification with Guidance for use. Geneva.

- LEAF (1995) Guidelines for Integrated Crop Management.

- Lee, J.J., Callaghan, P.O. \& Allen, D. (1995) Critical Review of Life Cycle Analysis and Assessment Techniques and their Application to Commercial Activities. Resources, Conservation and Recycling 13, 3756

- Leopold, L.B., Clark, F.F., Hanshaw, B.B. \& Balsley, J.R. (1971) A Procedure for Evaluating Environmental Impact. US Geological Survey Circular 645 Department of the Interior, Washington DC.

- Lewis, K.A., Tzilivakis, J., Skinner, J.A., Finch, J., Kähö, T.M., Newbold, M.J. \& Bardon, K.S. (1997)

Scoring and ranking farmland conservation activities to evaluate environmental performance and encourage sustainable farming. Sustainable Development, 5, 71-77

- Lewis, K.A., Newbold, M.J., Hall, A.M. and Broom, C.E. (1997b) An eco-rating system for optimizing pesticide use at farm level: Part I - Theory and Development. In press to J. Agricultural Eng. 1997

- Lewis, K.A., Newbold, M.J. and Broom, C.E. (1997c) An eco-rating system for optimizing pesticide use at farm level: Part 2 - Results and Discussion. In press to J. Agricultural Eng. 1997

- Lord, E (1992) Modelling of Nitrate Leaching: Nitrate Sensitive Areas. Aspects of Applied Biology: Nitrate and Farming Systems 30, 19-28

- MAFF - Ministry of Agriculture, Fisheries and Food (1991, 1992 \& 1993) Codes of Good Agricultural Practice for the Protection of Water, Air and Soil PB0587, PB0618 \& PB0617 MAFF Publications, London.

- MAFF - Ministry of Agriculture, Fisheries and Food (1994). Fertiliser Recommendation for Agriculture and Horticulture. 6th Edition MAFF Reference Book RB209. MAFF Publications, London

- MAFF \& HSC - Ministry of Agriculture, Fisheries and Food \& the Health and Safety Commision (1990) Code of Practice for the Safe Use of Pesticides on Farms and Holdings. HMSO, London.

- Midmore, P. \& Lanstaff, L. (1995) Measuring the Environment. New Farmer and Grower 48, Summer Issue, 22-23

- Munn, R.E. (1979) Environmental Impact Assessment, Principles and Procedures. Scope 5. ICSU Chichester, John Wiley and Sons.

- Murry, J.W. \& Hammons, J.O. (1995) Delphi: A Versatile Methodology for Conducting Qualitative Research. Review of Higher Education Summer 1995, 18, 4, 423-436

- Newbold, M.J., Lewis, K.A.,Tzilivakis, J., Finch, J., Kaho, T.M., Skinner, J.A. \& Bardon, K.S. (1997) The Options for Informal Environmental Management: The Agricultural Industry Highlighted. Eco-Management and Auditing Journal. 4, 1, 22-27

- OECD - Organisation for Economic Cooperation and Development (1991) Environmental Indicators 9-10, Paris

- Ott, W.R. (1978) Indices - Theory and Practice. Ann Arbor Science Publishers. Ann Arbor Mich. USA

- Pinder, L.C.V., House, W.A. \& Farr, I.S. (1993) Effects of Insecticides on Freshwater Invertebrates. The Environmental Effects of Pesticide Drift English Nature, 64-75 Ed.A.S. Cooke

- RBN (1996) Rural Business Network information leaflet. Email RBN@Farmline.com

- Reus, J.A. \& Pak, G.A. (1993) An Environmental Yardstick for Pesticides. Med. Fac. Landbouww. Univ. Gent. 58/2a, 249-255

- Solomon, R., Colbert, B.K., Hansen, W.J., Richardson, S.E., Canter, L. \& Vlachos, E.C. (1977) Water Resources Assessment Methodology (WRAMM) Impact Assessment and Alternative Evaluation. Technical Report. Y-77-1 US Army Corps of Engineers, Vicksburg.

- Taylor, A.W. (1995) The Volatilisation of Pesticide Residues. Environmental Behaviour of Pesticides. Chapter 6, 9, John Wiley \& Sons, Eds TR Roberts \& PC Keary.

- Thompson, M.A. (1990) Determining Impact Significance in EIA: A Review of 24 Methodologies. Journal of Environmental Management 30, 235-250

- UNED - United Nations Environment and Development (1994) UK Round Table on Land, Sustainable Agriculture and Rural Development: Chapter 14 and related sections of the United Nations Rio Summit Agenda 21. Discussion paper of the Sub-Group on Production Systems.

- Van der Werf, H. \& Zimmer, C.(1996) Assessing the Impact of Pesticides on the Environment using an Indicator based on Fuzzy Coded Variables. 4th ESA Congress, ESA Colmar, France, 716-717 


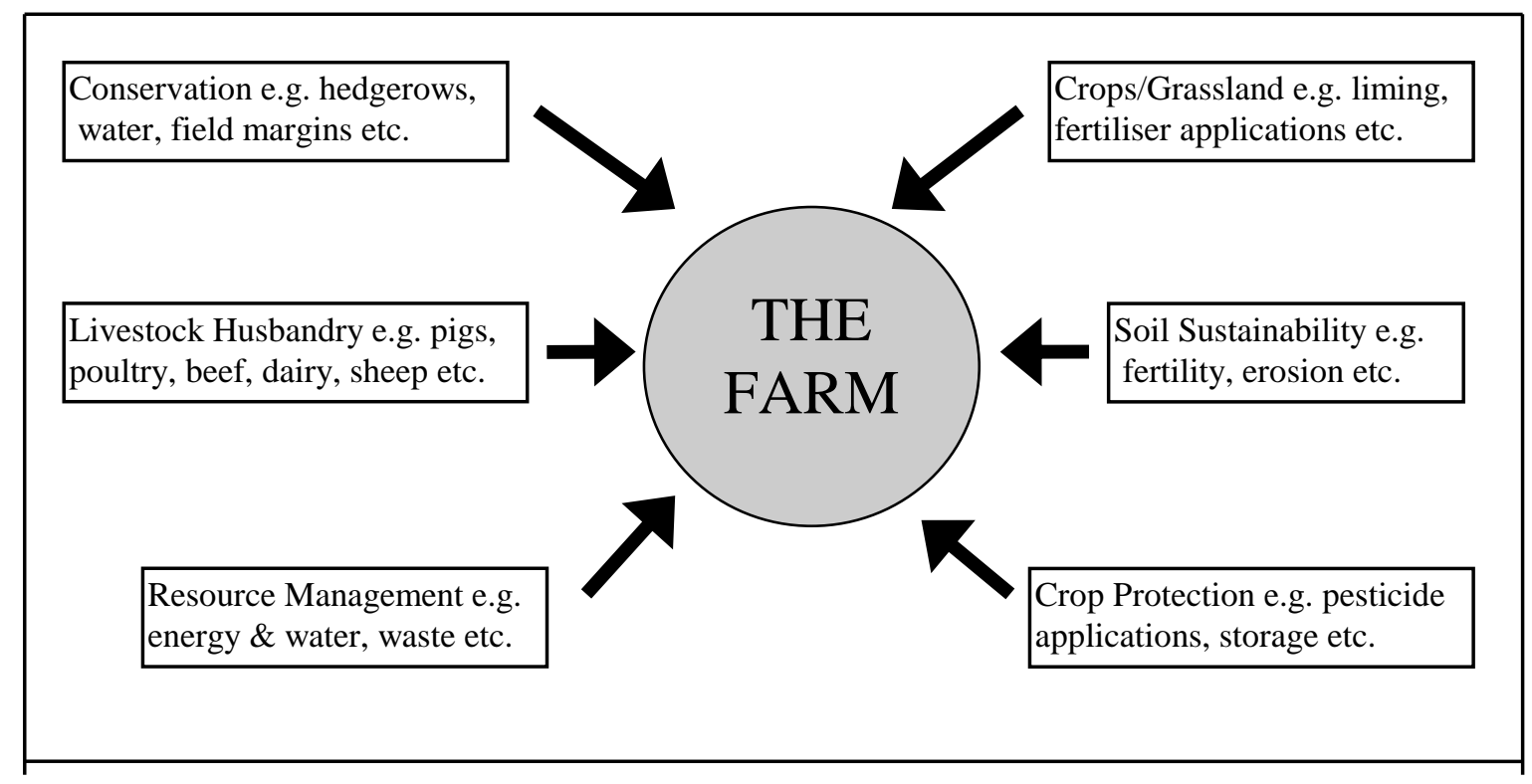

Figure 1: Illustrating the Main Farm Activities 
Figure 2: The EMA Eco-rating Summary Screens 


\section{Technical System}

* Fertiliser Needs

* Erosion Risk

* Pesticide Database

* Soil Type Database

* Climate Data

* Waste Advisor

* Pesticide Risk

\section{- Pesticide Risk}

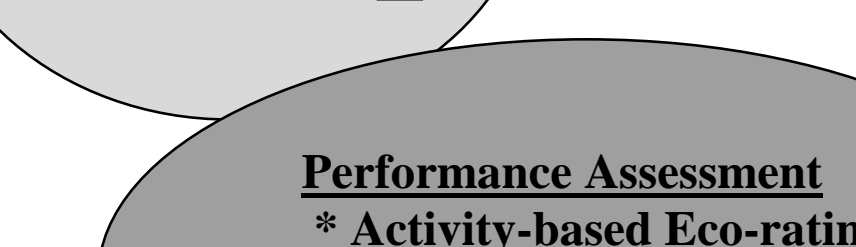

* Activity-based Eco-ratings

* Text Report

* Emissions Inventory
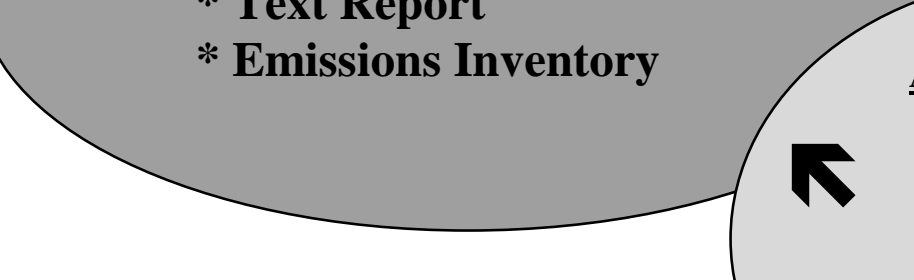

Advisory System

* Regulation

* Codes of Practice

* Env. Mgmt.

* Info Library

* Glossary, Index

* Contacts Database

Figure 3: Schematic Diagram Showing the Structure of the Computer System 
Figure 4: The EMA farm profile screen 


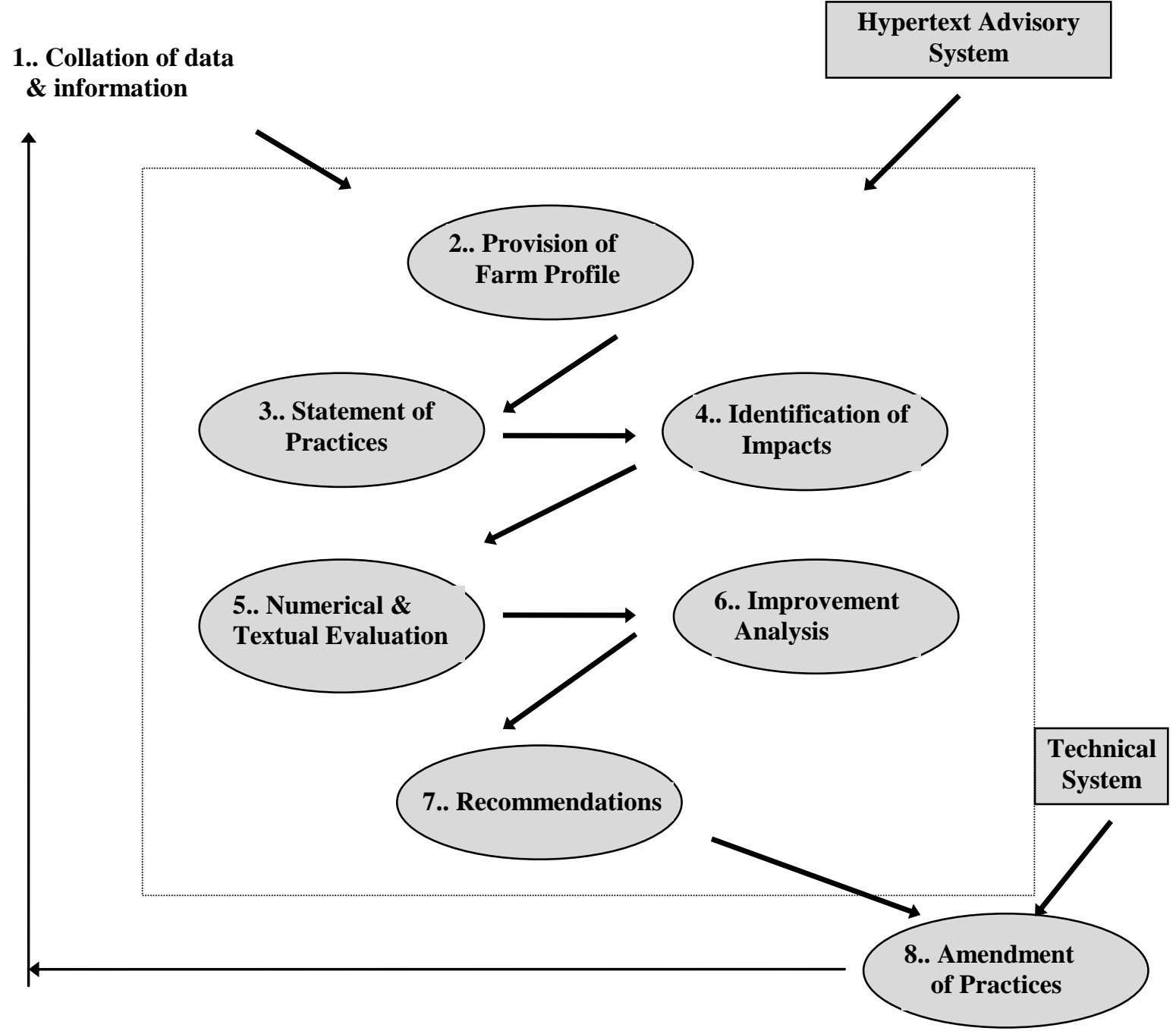

Figure 5: The EMA Flowchart 
Table 1: The Main Tasks Associated with using Pesticides for Crop Protection

\begin{tabular}{|c|c|}
\hline Task no. & Task* Description \\
\hline $\begin{array}{l}1 \\
\mathrm{a} \\
\mathrm{b} \\
\mathrm{c}\end{array}$ & $\begin{array}{l}\text { Pre-spraying activities e.g.: } \\
\text { - pest identification } \\
\text { - infestation \& damage assessment } \\
\text { - assessment of weather \& environmental conditions }\end{array}$ \\
\hline 2 & Spray preparation \\
\hline $\begin{array}{l}3 \\
\mathrm{a} \\
\mathrm{b} \\
\mathrm{c}\end{array}$ & $\begin{array}{l}\text { Application activities e.g.: } \\
\text { - choice \& use of spray equipment } \\
\text { - choice \& use of protective clothing \& equipment } \\
\text { - technique used (hand held sprayer, aerial app., etc.) }\end{array}$ \\
\hline $\begin{array}{l}4 \\
\mathrm{a} \\
\mathrm{b}\end{array}$ & $\begin{array}{l}\text { Post-spraying activities e.g.: } \\
\text { - checking for run-off, ponding etc. } \\
\text { - checking for contamination of non-target areas }\end{array}$ \\
\hline $\begin{array}{l}5 \\
\mathrm{a} \\
\mathrm{b} \\
\mathrm{c}\end{array}$ & $\begin{array}{l}\text { Environmental activities e.g.: } \\
\text { - leaving field margins unsprayed } \\
\text { - protection of sensitive features } \\
\text { - use of other forms of pest control e.g. bio- }\end{array}$ \\
\hline $\begin{array}{l}6 \\
\mathrm{a} \\
\mathrm{b} \\
\mathrm{c} \\
\mathrm{d}\end{array}$ & $\begin{array}{l}\text { Management activities e.g.: } \\
\text { - stock, storage and handling procedures } \\
\text { - record keeping } \\
\text { - waste management (conc. \& dilute solutions, empties) } \\
\text { - equipment maintenance \& servicing }\end{array}$ \\
\hline
\end{tabular}

* NB: Tasks also include pesticide selection, application rate and assessment of local conditions. These are included in the quantitative assessment of impact. 
Table 2: Examples of Pesticide Warning Labels and Assigned Impact Scores

\begin{tabular}{|l|l|c|}
\multicolumn{1}{|c|}{ Target } & \multicolumn{1}{c|}{ Label examples (BCPC, 1997) } & $\begin{array}{c}\text { Examples of } \\
\text { Severity Score }\end{array}$ \\
\hline Humans (COSHH) & 1 - Medical restrictions - Anticholinestestase organophosphate & 10 \\
Labels 1 - 13 & 3 - Very Toxic & 5 \\
& 4 - Toxic & 4 \\
& 5 - Harmful & 3 \\
6 - Irritant & 2 \\
\hline Animals \& birds & 45 - Dangerous to game, wild birds and animals & 5 \\
Labels 40 - 47 & 46 - Harmful to game, wild birds and animals & 4 \\
\hline Bees & 48 - Extremely dangerous to bees ... & 5 \\
Labels 48 - 50 & 48 \& 49 - Dangerous to bees ... & 4 \\
& 50 - Harmful to bees .... & 3 \\
\hline Aquatic species & 51 - Extremely dangerous to fish... & 5 \\
Labels 51 - 57 & 51 - Extremely dangerous to higher aquatic plants... & 5 \\
& 52 - Dangerous to fish.... & 4 \\
\hline Handling \& waste & 53 - Harmful to fish... & 3 \\
mgmt. & 16 - Remove contaminated clothing immediately & 1 \\
Labels 14 - 39, 58 - 71a & 71 - Do not burn container & \\
\hline
\end{tabular}


Table 3: Translation of Visual Information on Wind Speed into a Numerical Representation

\begin{tabular}{|l|l|l|}
\hline \multicolumn{1}{|c|}{ Visual signs } & \multicolumn{1}{c|}{ Description } & \multicolumn{1}{c|}{ Wind speed } \\
\hline Smoke rises vertically & Calm & $2-3 \mathrm{~km} / \mathrm{hr}$ \\
\hline Direction shown by smoke gently drifting & Light air movement & $3-6 \mathrm{~km} / \mathrm{hr}$ \\
\hline Leaves rustle and wind is felt on face & Light breeze & $6-10 \mathrm{~km} / \mathrm{hr}$ \\
\hline Leaves and twigs in constant motion & Gentle breeze & $10-15 \mathrm{~km} / \mathrm{hr}$ \\
\hline $\begin{array}{l}\text { Small branches move, wind raises dust and } \\
\text { loose paper }\end{array}$ & Moderate wind & $>15 \mathrm{~km} / \mathrm{hr}$ \\
\hline Trees bend and sway & Very windy & \\
\hline
\end{tabular}




\section{$\underline{\text { Table 4a : Farm Case Study - Pesticides Programme }}$}

Hypothetical Field Conditions: Clay soil, sugar beet, 15 ha in area, no principal aquifer, no surface waters within $10 \mathrm{~m}$ of field boundary, slightly moist soil, no buffer zones

\begin{tabular}{|c|c|c|c|c|c|c|}
\hline & $\begin{array}{l}\text { Pesticide } \\
\text { applied }\end{array}$ & Type & $\begin{array}{c}\text { Rate } \\
\text { applied }\end{array}$ & Windspeed & Weather & Timing \\
\hline 1 & $\begin{array}{l}\text { fenpropidin \& } \\
\text { propoconazole }\end{array}$ & Fungicide & $0.7 \mathrm{l} / \mathrm{ha}$ & Force 1 & Warm \& Sunny & Late March \\
\hline 2 & lenacil & Herbicide & $0.4 \mathrm{l} / \mathrm{ha}$ & Force 1 & Warm \& Sunny & Late April \\
\hline 3 & $\begin{array}{l}\text { ethofumesate \& } \\
\text { phenmedipham }\end{array}$ & Herbicide & $2.2 \mathrm{l} / \mathrm{ha}$ & Force 4 & Cool \& Cloudy & Early May \\
\hline 4 & metamitron & Herbicide & $1.1 \mathrm{~kg} / \mathrm{ha}$ & Force 4 & Cool \& Cloudy & Early May \\
\hline 5 & metamitron & Herbicide & $2.2 \mathrm{~kg} / \mathrm{ha}$ & Force 3 & Cool \& Cloudy & Late May \\
\hline 6 & $\begin{array}{l}\text { ethofumesate \& } \\
\text { phenmedipham }\end{array}$ & Herbicide & 2.2 l/ha & Force 3 & Cool \& Cloudy & Late May \\
\hline 7 & metamitron & Herbicide & $0.5 \mathrm{~kg} / \mathrm{ha}$ & Force 1 & Warm \& Sunny & Mid June \\
\hline 8 & cypermethrin & Insecticide & $0.25 \mathrm{l} / \mathrm{ha}$ & Force 3 & Warm \& Cloudy & Early July \\
\hline
\end{tabular}

\section{Table 4b : Farm Case Study - Eco-Ratings Derived}

\begin{tabular}{|c|c|c|c|c|}
\hline & Pesticide applied & $\begin{array}{l}\text { Rate } \\
\text { applied }\end{array}$ & $\begin{array}{l}\text { Description of label precautions (see also } \\
\text { Table } 2\end{array}$ & Total $P_{f} \%$ \\
\hline 1 & $\begin{array}{ll}\text { fenpropidin } & \& \\
\text { propoconazole } & \end{array}$ & $0.7 \mathrm{l} / \mathrm{ha}$ & $\begin{array}{l}\text { A, C, } 5 a, 5 c, 6 b, 9,10 a, 14,16,18,23,29,35,36 \\
37,52,54 a, 63,66,70,78\end{array}$ & -100 \\
\hline 2 & lenacil & 0.4 l/ha & $\begin{array}{l}\text { A, C, } 6 a, 6 b, 6 c, 18,21,28,29,36,37,53,63,65 \text {, } \\
67\end{array}$ & -35 \\
\hline 3 & $\begin{array}{ll}\text { ethofumesate } \quad \& \\
\text { phenmedipha) }\end{array}$ & $2.2 \mathrm{l} / \mathrm{ha}$ & $\begin{array}{l}\text { A, C, } 5 a, 6 b, 6 c, 12 c, 16,21,28,29,36,37,53 \\
58,60,63,66,70\end{array}$ & -67 \\
\hline 4 & metamitron & $1.1 \mathrm{~kg} / \mathrm{ha}$ & $29,54,63,70$ & -47 \\
\hline 5 & metamitron & $2.2 \mathrm{~kg} / \mathrm{ha}$ & $29,54,63,70$ & -75 \\
\hline 6 & $\begin{array}{l}\text { ethofumesate \& } \\
\text { phenmedipham }\end{array}$ & $2.2 \mathrm{l} / \mathrm{ha}$ & $\begin{array}{l}\text { A, C, } 5 a, 6 b, 6 c, 12 c, 16,21,28,29,36,37,53 \text {, } \\
58,60,63,66,70\end{array}$ & -59 \\
\hline 7 & metamitron & $0.5 \mathrm{~kg} / \mathrm{ha}$ & $29,54,63,70$ & -28 \\
\hline 8 & cypermethrin & $0.25 \mathrm{l} / \mathrm{ha}$ & $\begin{array}{l}\text { A, C, 5a, 5c, 6a, 6b, 12c, 14, 18, 21, 24, 28, 29, 36, } \\
37,48,51,63,66,70,78\end{array}$ & -25 \\
\hline & Field Value & & & -62 \\
\hline
\end{tabular}

Note 1: COSHH - refers to substances described as hazardous under the 1988 Control of Substances Haradous to Health Regulations. 